\title{
DIGITAL \\ Frontiers in Heat and Mass Transfer \\ EFFECT OF ASPECT RATIO ON SUPERCRITICAL HEAT TRANSFER OF CRYOGENIC METHANE IN ROCKET ENGINE COOLING CHANNELS
}

\author{
M. Arun, J. Akhil, K. Noufal, Robin Baby, Darshitha Babu, M. Jose Prakash* \\ Dept. of Mechanical Engineering, TKM College of Engineering, \\ Kollam- 691005, Kerala, India
}

\begin{abstract}
The supercritical turbulent flow of cryogenic methane flowing in a rocket engine cooing channel is numerically analysed by imposing constant heat flux at the bottom surface of the channel. The calculation scheme is validated by comparing the results obtained with experimental results reported in literature. The heat transfer coefficient is influenced by the strong variation in thermophysical properties of methane at super critical pressure. An increasing trend in the average value of Nusselt number is observed with aspect ratio. The efficacy of both Modified Jackson and Hall and Bishop empirical correlations in predicting Nusselt number is tested for cryogenic methane flowing in coolant channels.
\end{abstract}

Keywords: cryogenic rocket engine, Regenerative cooling, Heat transfer deterioration

\section{INTRODUCTION}

Regenerative cooling is the most commonly used cooling technique used for Liquid Rocket Engine(LRE) thrust chambers. Majority of the rocket engines use fuel as the coolant, which is circulated through the narrow rectangular cooling channels to cool the thrust chamber wall and simultaneously recover a major amount of lost energy of combustion products. The fuel which flows through the channel reaches the injector face, from where it is injected to the combustion chamber at a pressure higher than the chamber pressure. In high pressure rocket engines a small quantity of fuel is injected through small orifices as film coolant to protect the combustion chamber wall from localised heating. In most of the engines the pressures of the fuel in the cooling channels are well above its critical pressure. As the temperature of the fuel flowing at supercritical pressure increases during the regenerative cooling process, it would not undergo a phase change; instead its state changes from a liquid like to a gas like state with drastic variation in thermophysical properties. The temperature at which this phenomenon occurs is known as pseudocritical temperature corresponding to a supercritical pressure.

Nowadays methane is considered as an alternative fuel for rocket engine applications. Methane is available in many planets and it can be harvested for carrying out interplanetary missions. The cryogenic methane has like higher density (means smaller storage tank) and higher vaporization temperature compared to cryogenic hydrogen. Methane has higher specific impulse, higher coking limit and superior cooling capability compared to kerosene. The earlier studies on supercritical heat transfer phenomena were mainly focused on fluids like water Yamagata et al. (1974), Koshizuka et al. (1995) Lee et al. (1996) and carbon dioxide Liao et al.(2002), Jiang et al. (2004) He et al.(2005) because of their industrial applications in the field of steam boilers, nuclear reactors and in refrigeration and air conditioning industries. Carlile and Quentmeyr (1992) conducted experimental studies to see the effect of aspect ratio on hot gas side wall temperature. They presented the results for a straight channel with gaseous hydrogen as the coolant and showed that the high aspect ratio cooling passages are showing lesser fatigue damage to the hot gas side wall. Woschnak et al. (2003) developed a new solution strategy, called quasi 2-D approach which takes into account thermal stratification. Pizzarelli et al. (2007, 2008, 2009a, 2009b, 2010, 2011, 2012, 2013a, 2013b, 2014, 2015) conducted a number of numerical studies to predict coolant flow and heat transfer deterioration in coolant channels with cryogenic methane as the fluid. They developed a simplified model to evaluate the thermal stratification in solid fin as well as the coolant. They also studied the effect of aspect ratio on rectangular as wells as the curved cooling channels to predict the wall temperature and wall heat flux distribution with cryogenic methane as the fluid under transcritical conditions. Through a 2-D axisymmetric study on a circular channel they focussed on heat transfer deterioration aspects of the coolant at transcritical conditions. Urbano et al. (2009) suggested that fluids at transcritical state undergo large changes in properties in the channel. They identified that in addition to the semi empirical correlations available in literature, some other parametric studies will be necessary so as to understand the sensitivity of wall temperature peak. Numerical studies on convective heat transfer of n-heptane was done by Hua et.al (2010) Their results clearly indicate that heat transfer deterioration could occur once the wall temperature reaches pseudocritical temperature. They found that expressions for estimating the heat transfer coefficient for carbon dioxide and water can generally be applied for supercritical of n-heptane when the inlet velocity more than $10 \mathrm{~m} / \mathrm{s}$. It is evident from past studies that it is difficult to obtain a unique heat transfer correlation for fluids flowing at supercritical pressures. A modified heat transfer expression which is applicable to the supercritical heat transfer of cryogenic methane flowing inside a horizontal mini tube with constant wall heat flux was established by Wang et.al (2010). The density of cryogenic methane was calculated precisely with the help of a Modified Benedict-Webb-Rubin (MBWR) equation with 15 coefficients. The coefficients of MBWR and thermal conductivity were taken from the models established by Ely and Hanley (1981, 1983). The properties of methane at different supercritical pressures have been reported by Younglove and Ely (1987). Urbano and Nasuti $(2012,2013)$ analysed the heat transfer capabilities of methane by a parabolized Navier-Stokes solver which includes an accurate equation of state as well as property models, able to describe methane in all thermodynamic states of interest. Ruan and Meng (2012) conducted numerical analyses on the flow and heat transfer of cryogenic methane flowing in a rectangular coolant channel. Their studies do not consider

\footnotetext{
${ }^{*}$ Corresponding author. Email: josetkm@tkmce.ac.in
} 
the wall thickness of the coolant channel and their results illustrated that heat transfer deterioration phenomena could occur during a supercritical heat transfer process owing to property variation anomaly near the pseudocritical temperature at the near wall zone. The study on rectangular channels was extended by Wang et al. (2013) by considering the thickness of the wall and thermal conductivity of wall material. Their studies indicate that the thermal conductivity of the wall material has a significant effect on conjugate heat transfer due to heat flux redistribution in the solid region. Trejo et al. (2013, 2014) experimentally investigated the heat transfer characteristics of liquid methane flowing in channels of square and rectangular cross sections and the results are in good agreement with NASA/Rocket dyne Nusselt number correlation. Hungfang et al.(2013) experimentally investigated heat transfer of supercritical cryogenic methane in a miniature tube. They developed a semi-empirical new correlation, evaluated by PDF based time-averaged properties for convection heat transfer of cryogenic methane. Their model is able to capture the $85 \%$ of experimental data within the permissible error limits. Votta et al. (2016) conducted experimental studies and proposed a correlation for determining the Nusselt number, which is valid for asymmetrically heated rectangular channels. Pizzarelli (2016) proposed a Nusselt number correlation to describe the convective heat-transfer characteristics of supercritical flow exhibiting deterioration and with negligible buoyancy effects from numerical simulations.

In the present numerical study the conjugate heat transfer of cryogenic methane flowing in a rocket engine cooling channel at supercritical pressure with asymmetrical heating imposed on the bottom surface is considered. Due to the similarity of the coolant channel with that of an actual rocket engine, the results obtained herein are beneficial for the design and optimization of rocket engine cooling systems. The multi-dimensional heat conduction in engine wall is analyzed using the fin effect of cooling channel side walls. The rocket engine inner wall is usually made of alloys of copper which is having high relatively thermal conductivity. The variation of thermal conductivity of the channel wall material with temperature is also considered. Studies have been conducted to see the effect of Aspect Ratio (AR) on the heat transfer and wall temperature distribution. The Aspect ratio is varied without changing the area of flow. The values of Nusselt number is compared with that obtained from Bishop equation and Modified Jackson and Hall empirical correlations.

\section{THEORETICAL FORMULATION AND NUMERICAL APPROACH}

Generally rocket engine cooling channel dimensions are in the order of $\mathrm{mm}$. In the present study the coolant channel of a subscale rocket engine thrust chamber, Jose Prakash et al. (2012) is considered. The geometry of the computational domains and the boundary conditions are illustrated in Fig. 1. A detailed discussion on the geometry with boundary conditions is given in the next section.

The following conservation equations of mass, momentum and energy are numerically solved in the fluid phase

$\nabla \cdot(\rho \boldsymbol{u})=0$

$\nabla \cdot(\rho \boldsymbol{u u})=-\nabla p+\nabla \cdot \tau_{\text {eff }}$

$\nabla \cdot\left(\rho \boldsymbol{u} e_{t}\right)=\nabla \cdot\left(\lambda_{e f f} \nabla T\right)-\nabla \cdot(p \boldsymbol{u})$

Since the flow velocity is low, the viscous heating term in the energy equation is neglected. Standard k- $\varepsilon$ turbulent model with an enhanced wall treatment available with ANSYS Fluent 14.5 (2012) is employed for treating turbulent flow. The thermal conduction equation is incorporated to accommodate the effects of conjugate heat transfer.

$\nabla \cdot(\lambda \nabla T)=0$

This equation is coupled with energy transport equation in the fluid phase through interface boundary conditions.

The main issue in analysing fluid flow and heat transfer at supercritical state is to accurately calculate the thermophysical properties. The thermodynamic properties of methane are given in Table 1.

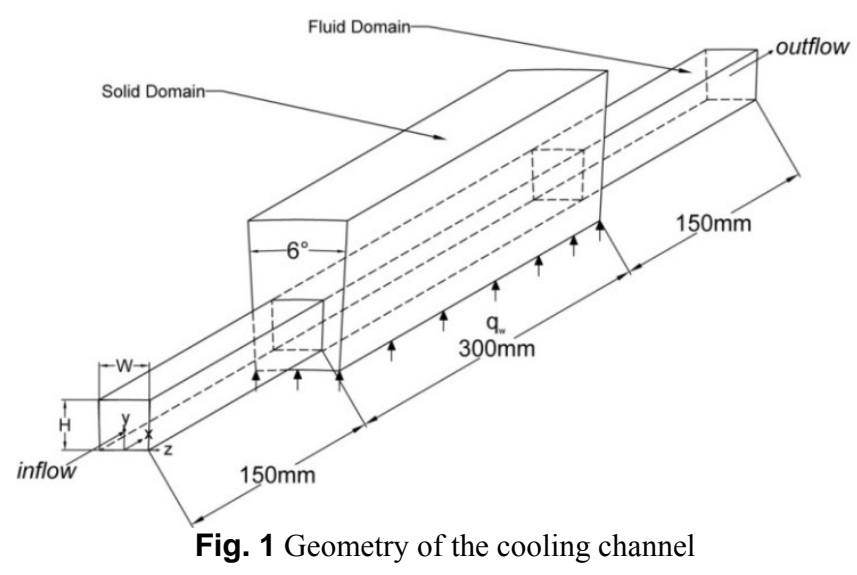

Table 1 Thermodynamic Parameters of Methane

\begin{tabular}{|l|c|}
\hline \multicolumn{1}{|c|}{ Parameters } & Values \\
\hline Mol. Wt.( g/mol) & 16.04 \\
\hline Critical Temperature $(\mathrm{K})$ & 190.4 \\
\hline Critical Pressure $(\mathrm{MPa})$ & 4.6 \\
\hline Critical Volume $\left(\mathrm{cm}^{3} / \mathrm{mol}\right)$ & 99.2 \\
\hline Critical Compressibility factor & 0.288 \\
\hline Accentric factor & 0.011 \\
\hline
\end{tabular}
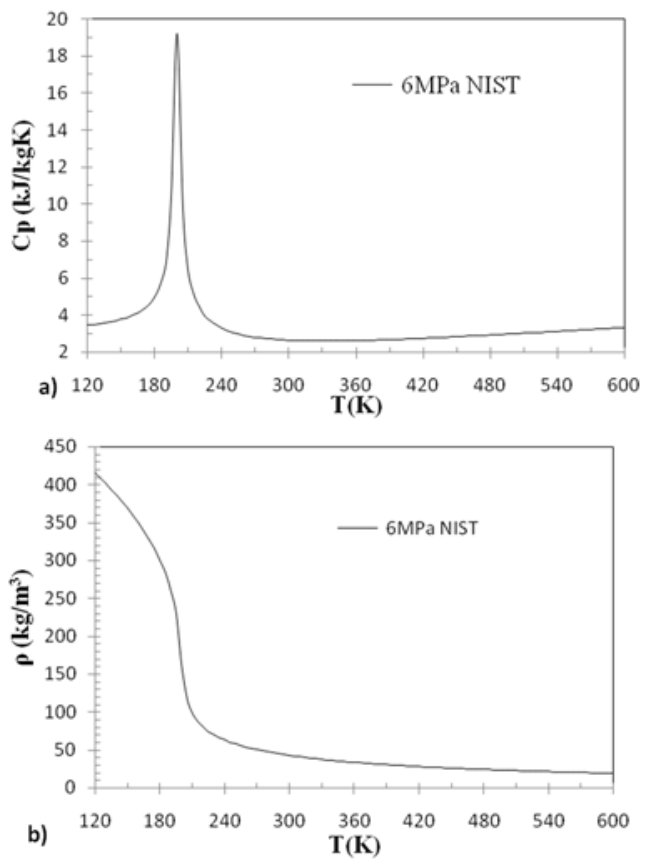

Fig. 2 Thermophysical properties of methane with temperature a) Specific heat capacity b) density

Generally the coolant inside the regenerative channels are at super critical pressures. For the present study the pressure inside the coolant channel is taken as $6 \mathrm{MPa}$. It is observed that for the pressure of $6 \mathrm{MPa}$ the specific heat at constant pressure is maximum at $200 \mathrm{~K}$. The variations of thermo physical properties of methane at $6 \mathrm{MPa}$ pressure is illustrated in Fig 2. Wang et al.( 2010) suggested that a modified Bendict-Webb-Rubin(BWR) equation of state with 15 coefficients can be used to obtain the density of methane accurately. Modified BWR accurately predicts the density of methane at low temperature and high pressure than other traditional Equations of State(EoS). However there is a maximum of $0.2 \%$ error between the calculated and experimental densities over the entire extended PVT surface Ely and Hanley (1981). 
For the present study the values of heat capacity, density, thermal conductivity and viscosity of cryogenic methane are taken from NIST data base and are incorporated into the numerical simulation (through interpolation functions) as User Defined Functions(UDF) for better accuracy. The thermal conductivity variations of the chamber wall material Copper, Simon et al.(1992) is illustrated in Fig 3.

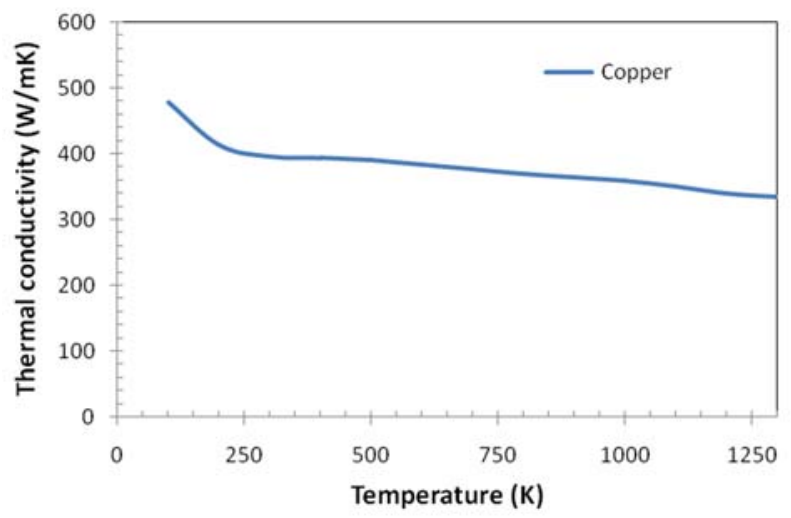

Fig. 3 Variation of thermal conductivity of copper with temperature

\section{MODELLING AND SIMULATION}

For the present study the geometry considered is the coolant channel of a subscale rocket engine thrust chamber, Jose Prakash et al. (2012) with constant chamber wall thickness. The inner and outer radii of the combustion chamber are $47.8 \mathrm{~mm} 56.8 \mathrm{~mm}$ respectively. The number of coolant channels is fixed as 60 . Due to the geometrical symmetry of the combustion chamber a sectoral portion of $6^{0}$ is chosen for the preparation of the computational domain. The details of the geometry considered are illustrated in Fig. 4.

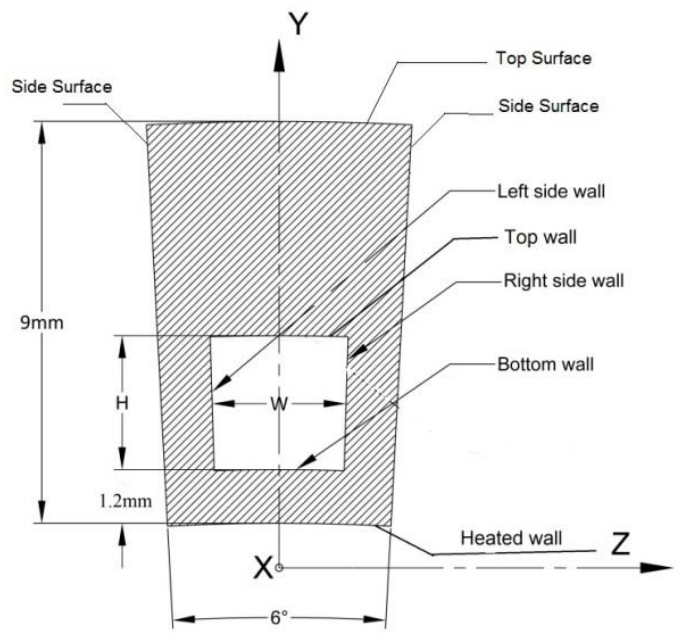

Fig. 4 Dimensions of Channel Cross-Section

In order to study the effect of Aspect Ratio (AR) on the heat transfer characteristics five cases have been considered. The details are shown in Fig. 5 and table 2. In all the cases the combustion chamber wall thickness is fixed as $9 \mathrm{~mm}$, the wall thickness at the bottom of the coolant channel as $1.2 \mathrm{~mm}$ and channel area of flow (A) as $9 \mathrm{~mm}^{2}$. The area of the channel kept constant so that the velocity of flow is same. The five different aspect ratios are obtained by varying channel height $(\mathrm{H})$ and width (W). An entry length of $150 \mathrm{~mm}$ is provided to obtain a fully developed flow inside the coolant channel as in Fig.1. In order to avoid the effect of outlet boundary condition, an exit section with a length of $150 \mathrm{~mm}$ is provided. The test section which is $300 \mathrm{~mm}$ in length is asymmetrically heated with a constant wall heat flux of $5 \mathrm{MW} / \mathrm{m}^{2}$ on the bottom surface of the solid part which is referred as heated wall. The top surface of the coolant channel is assumed to adiabatic and symmetry boundary conditions are applied at the side surfaces of the coolant channel. The inlet velocity and temperature are taken as $15 \mathrm{~m} / \mathrm{s}$ and $120 \mathrm{~K}$ respectively. The absolute pressure of the coolant at the outlet is taken as $6 \mathrm{MPa}$.

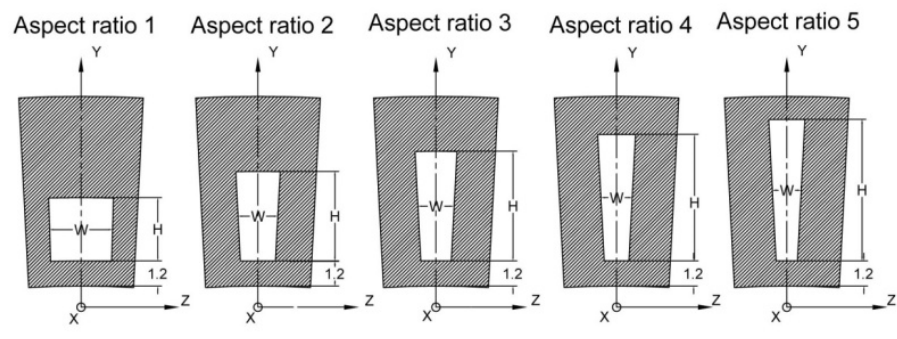

Fig. 5 Channel cross sections with different AR

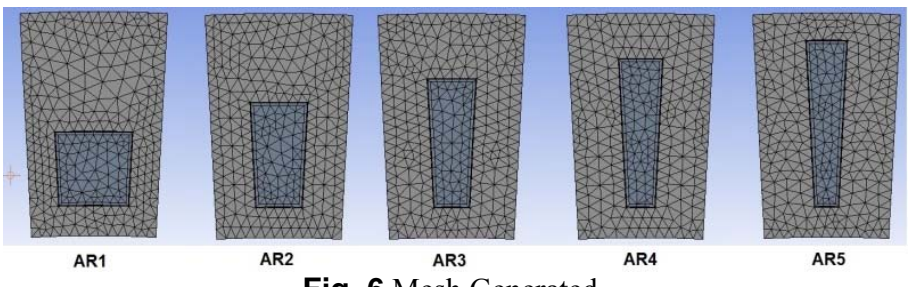

Fig. 6 Mesh Generated

Table 2 Dimensions of the flow area at various Aspect Ratios

\begin{tabular}{|c|c|c|}
\hline Aspect Ratio & $H$ & $W$ \\
\hline 1 & 3 & 3 \\
\hline 2 & $3 \sqrt{2}$ & $3 / \sqrt{2}$ \\
\hline 3 & $3 \sqrt{ } 3$ & $\sqrt{3}$ \\
\hline 4 & 6 & $3 / 2$ \\
\hline 5 & $3 \sqrt{5}$ & $3 / \sqrt{5}$ \\
\hline
\end{tabular}

Patch conforming tetrahedral elements are used for the domain preparation. The details of grids are represented in Fig. 6.Grid independence studies have been conducted before the detailed numerical analysis. Grid system having an element size of $4 \times 10^{-04} \mathrm{~m}$ is found sufficient to produce reliable numerical results. For all the grids the skewness is kept below the permissible limit of 0.85 . The boundary layer resolution near the walls are optimized by using the inflation option available with ANSYS Meshing 14.5 (2012). Since k- $\varepsilon$ turbulent model with an enhanced wall treatment has been applied, care is taken to keep the $y+$ values for all the fluid and solid interfaces satisfying a value of $y+$ $\leq 1$. This is done to accurately capture the sharp temperature gradient in the near wall region at supercritical pressures.

\section{RESULTS AND DISCUSSION}

For model validation the results of experimental studies on heat transfer of supercritical carbon dioxide is considered due to the lack of reliable experimental data on supercritical heat transfer of cryogenic methane. The geometry used in the experiment of Jiang et al. (2004) was a circular pipe and the same geometry and boundary conditions were considered for validation. Figure 7 shows the data obtained from experiments and present study for supercritical heat transfer of carbon dioxide. The computed values show fair agreement with the experimental results with a maximum difference of $7 \%$.

The results obtained from the numerical studies of Ruan and Meng (2012) are reproduced and are shown in Fig. 8. Here the geometry was a rectangular coolant channel having no wall thickness with methane at supercritical pressure as the coolant. Figure 8.a shows the variation of wall temperature in the axial direction. The maximum difference between the temperatures obtained from the present study and that reported in literature is 5\%. Fig. 8.b shows the variation of bulk fluid temperature in the axial direction. The difference between the values obtained from the present study and that reported in the literature is marginal. 


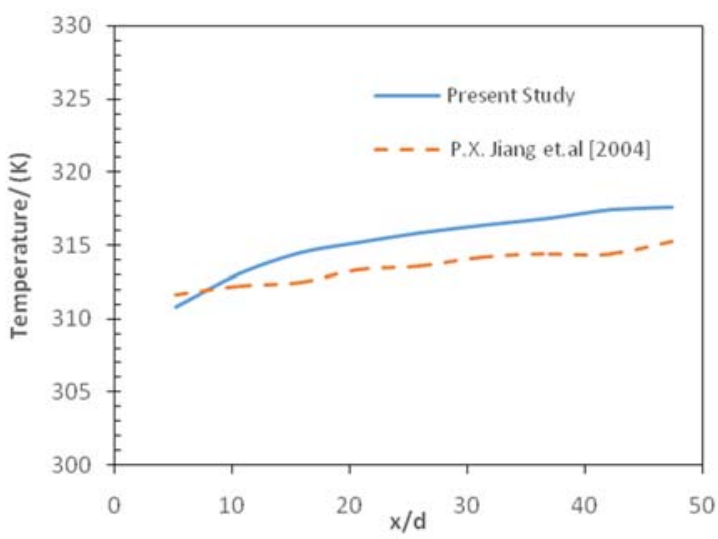

Fig. 7 Variation of wall temperature in the axial direction
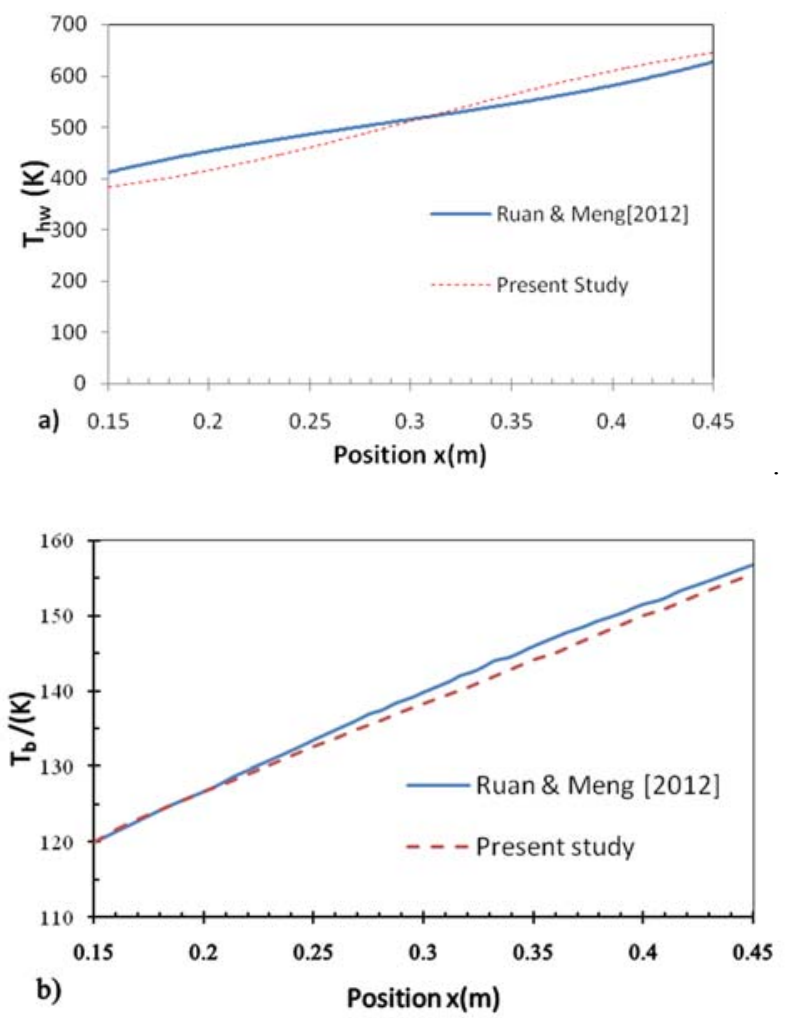

Fig. 8 Variation of temperature in the axial direction (a) heated wall temperature (b) bulk fluid temperature

\subsection{Flow Stratification}

Thermal stratification is a phenomenon that can be observed in high aspect ratio rocket engine coolant channels. In the present numerical study the aspect ratio is varied from 1 to 5 keeping the flow area of the channel constant. The mass flux $(\mathrm{G})$ through the coolant channel is also kept constant. An increase in aspect ratio will result in an increase in perimeter of the channel which in turn reduces the equivalent diameter. The heat transfer coefficient is related to the mass flux and the equivalent diameter as

$$
h \sim \frac{G^{0.8}}{D_{h}^{0.2}}
$$

For a given mass flow rate and cross sectional area, increase in aspect ratio will result in increase in heat transfer coefficient which in turn reduces the wall temperature. Generally this prediction will lead to the conclusion that higher aspect ratio will produce better cooling than lower aspect ratio and technical difficulties in machining of narrow channels put a limit for this. But this is not true when heat fluxes are asymmetrically distributed around the channel perimeter. Once the temperature distribution is varying, non-homogeneous coolant mixing can be observed in the channel. This phenomenon is referred as thermal stratification.

The thermal stratification will definitely depend on the type of wall material, the type of coolant and the state at which it enters the channel. Fluids flowing at supercritical state will experience drastic changes in its properties once the temperature reaches the critical range. This near critical property changes also influence the heat transfer capacity of the coolant.

The contours of temperature at various cross sections of the channel in the flow direction for both solid wall and fluid phase are illustrated in Fig.9. With increase in AR the contact area between the wall and fluid increases and the fin effect becomes predominant. Also there is reduction in thermal resistance due to the increase in side wall thickness which in turn improves the heat conduction. From the present study it is observed a more homogeneous heating of the coolant is visible at high aspect ratios due to the better heat flux redistribution. And temperature is unifrom near the exit region for higher aspect ratios. For aspect ratio 1 the average temperatures of the bottom, side and top walls are $413 \mathrm{~K}$, $377 \mathrm{~K}, 354 \mathrm{~K}$ and that for aspect ratio 5 it is $272 \mathrm{~K}, 236 \mathrm{~K}, 216 \mathrm{~K}$ respectively.

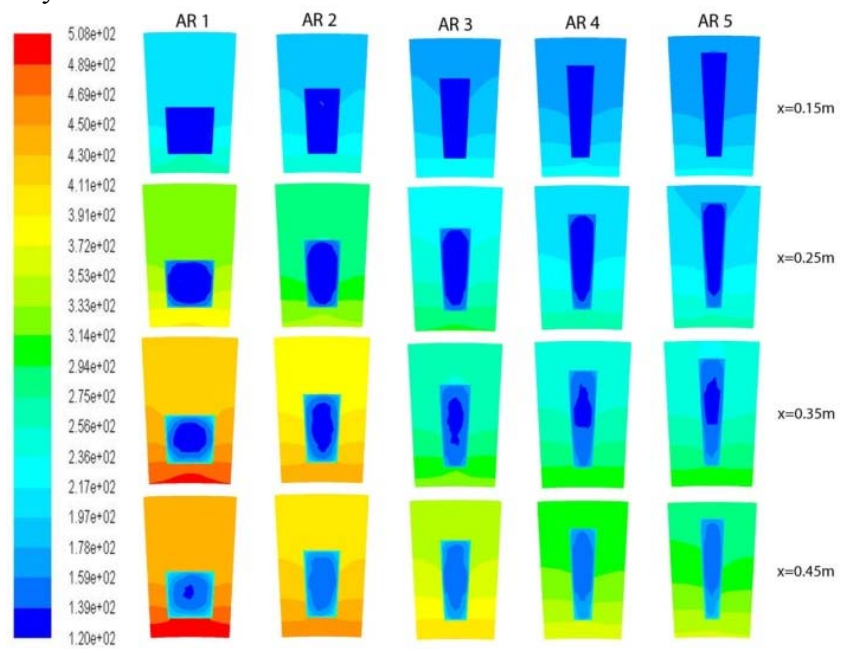

Fig. 9 Contours of temperature in the fluid and solid domains for different aspect ratios.

The methane entering the coolant channel at $120 \mathrm{~K}$ is having a density of $415 \mathrm{~kg} / \mathrm{m}^{3}$ and it decreases along the flow direction for all aspect ratios. Also there is significant variation in density in the radial direction as the aspect ratio is increased from 1 to 5 . The variation in average density along the flow direction at various radial distances from the bottom wall (y-axis) in the fluid domain is shown in fig.10. The average density at the bottom wall(RB) increases up to aspect ratio 4 and then decreases. Similar trends are observed for the fluid layers $0.1 \mathrm{~mm}$ above the bottom wall $(\mathrm{RB}=0.1), 0.1 \mathrm{~mm}$ below top wall $(\mathrm{RT}=0.1)$ and at the top wall (RT). However for the fluid layer at the centre of the channel (RC) there is no significant change in density. For the fluid layer at the bottom wall (RB) is having an average density of $37 \mathrm{~kg} / \mathrm{m}^{3}$ for aspect ratio 1 and it the corresponding value aspect ratio 4 is $65 \mathrm{~kg} / \mathrm{m}^{3}$. The high thermal stratification occurs mainly due to the property variations near the critical region. Due to the thermal stratification the liquid like methane having high density is transformed to gas like low density indicating the shift of the fluid layer near the bottom wall from supercritical liquid to supercritical gas. Once this shift occurs the fluid will cross the pseudocritical point after which the significant deterioration in fluid properties is observed.

Since all the wall temperatures of the present study shows a slight higher temperature than the pseudocritical temperature $(\mathrm{Tpr}=200 \mathrm{~K}$ at $6 \mathrm{MPa}$ ) the fluid flowing nearer to the wall is having a reduced heat capacity. 


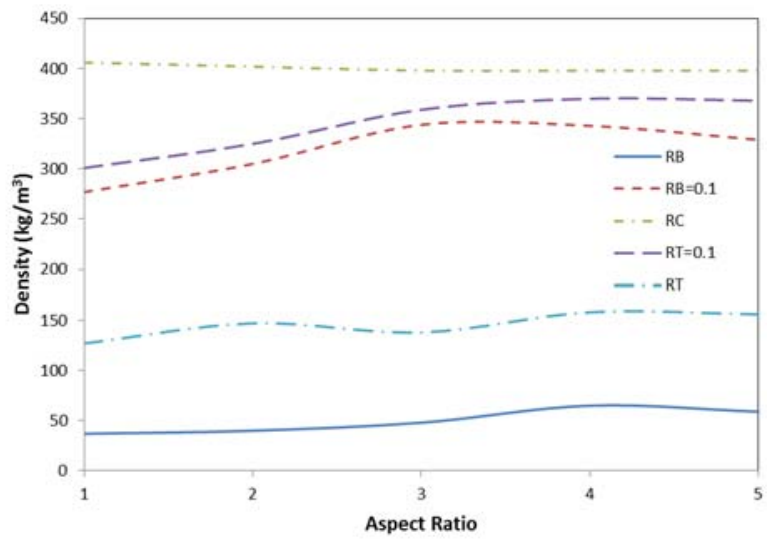

Fig. 10 Variation of density with aspect ratio.

Fig. 11 shows variation of the volumetric heat capacity of the fluid near the bottom wall in the flow direction. The volumetric heat capacity of the fluid throughout the length is more for aspect ratio 4 . This is a clear indication of better heat transfer for aspect ratio 4 than the others.

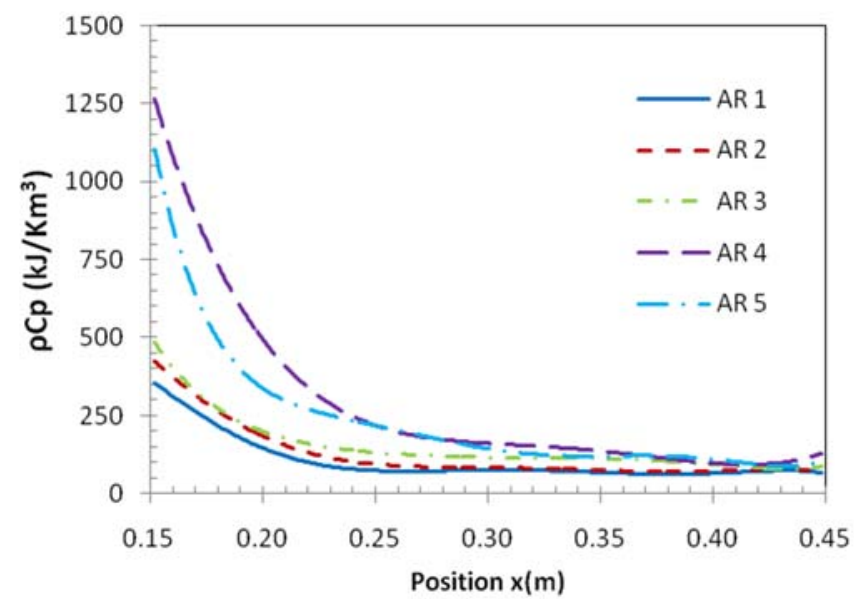

Fig. 11 Variation of the volumetric heat capacity at the bottom wall in the flow direction

\subsection{Variation of Bulk Fluid Temperature Along The Flow Direction}

The variation of bulk fluid temperature in the direction of flow with aspect ratios is shown in Fig. 12. Bulk fluid temperature is defined as

$T_{b}=\frac{\int_{A} \rho u C_{p} T d A}{\int_{A} \rho u C_{p} d A}$

The bulk fluid temperatures are almost same for all aspect ratios up to a distance of about $0.25 \mathrm{~m}$. However slight difference in temperatures is observed beyond $0.25 \mathrm{~m}$ and this may be due to the variation in specific heats.

\subsection{Effect of Aspect Ratio on Wall Temperature}

The combustion chamber walls are exposed to very high heat fluxes during the rocket engine operations this high heat energy must be absorbed by the regenerative coolant in order to provide better temperature distribution along the chamber walls. If the fluid layers adjacent to the wall are either at the critical region or nearer to it, there will be heat transfer deterioration due to the sudden property variation particularly in specific heat capacity and density. Also once the fluid layer adjacent to the wall crosses the pseudocritical point the heat carrying capacity of the fluid reduces due to the reduction in volumetric heat capacity.

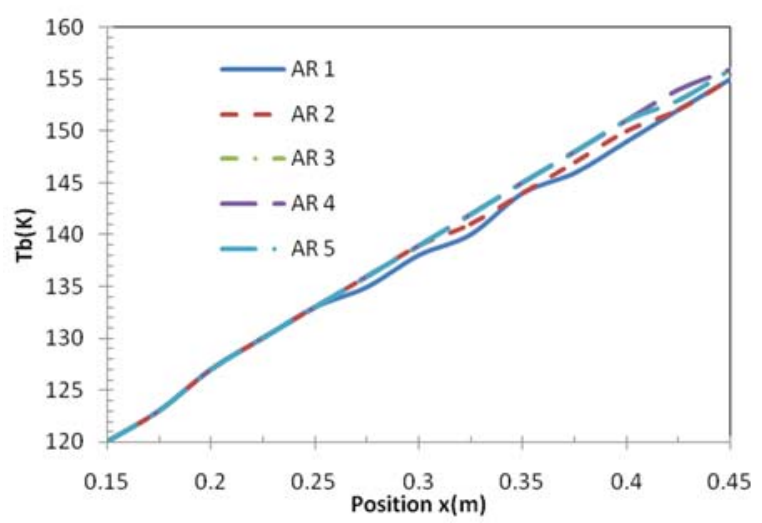

Fig. 12 Variations of bulk fluid temperature in the axial direction

The variation of the average temperature at the heated, bottom, side and top walls with aspect ratio is shown in Fig. 13. It is observed that the temperature of the heated wall for a given aspect ratio increases in the axial direction. As the aspect ratio increases from 1 to 5 the temperature of the heated wall decreases due to the improved heat flux redistribution caused by the reduction in thermal resistance of the wall. Reduction in thermal resistance is due to the increase in cross-sectional area of the side walls in the radial direction. This helps to provide better heat transfer through the high thermal conductivity copper walls than the low thermal conductivity fluid. The maximum value of heated wall temperature for aspect ratio 1 is $504 \mathrm{~K}$ and it decreases by $30 \%$ as the aspect ratio is increased from 1 to 5 . Similar trend is observed for other walls of the channel. Also as the aspect ratio increases the fin surface area of the side wall in radial direction increases this helps to provide better heat transfer through the side walls. For aspect ratio1, the average heat input transferred to the fluid through the bottom wall is $26 \%$ of the heat input and as the aspect ratio increases this quantity reduces. For example with aspect ratio 5 the amount of average heat input reaching the fluid through the bottom wall is only $6 \%$ of the imposed heat input and this is due to the better heat flux redistribution through the side walls. From Aspect ratio 3 onwards the more heat flux is transferred to the fluid through the side walls. When the aspect ratio is increased from 1 to 5 , average convective heat transfer coefficients at the bottom, side and top walls increases by $15 \%, 64 \%, 66 \%$ respectively. Enhancement in average heat transfer coefficient is a clear indication of reduction in heat transfer deterioration near the wall region for higher aspect ratios.

\subsection{Variation of Average wall Heat Transfer Coefficient With Aspect Ratio}

The variation of average heat transfer coefficient at the bottom, side and top walls of cooling channel with aspect ratios is shown in Fig. 14. It is observed that at all the walls, average heat transfer coefficient increases with $\mathrm{AR}$ and it is maximum for $\mathrm{AR}=4$. For all aspect ratios the bottom wall is having a lower heat transfer coefficient compared to other walls. This indicates that for all aspect ratios the fluid layers near to the bottom wall are either in the critical region or nearer to it. As the aspect ratio increases, the channel height and side wall thickness increase where as the top wall thickness decreases. This causes an increase in heat conduction through the side walls which in turn increases the heat flux through the side walls.

\subsection{Variation of Heat Transfer Coefficient At the Walls}

The heat transfer coefficient is defined as

$\mathrm{h}=\frac{q_{w}}{T_{w}-T_{b}}$

The heat transfer coefficients at the bottom, side and top walls along the flow direction for various aspect ratios are illustrated in Fig. 15 

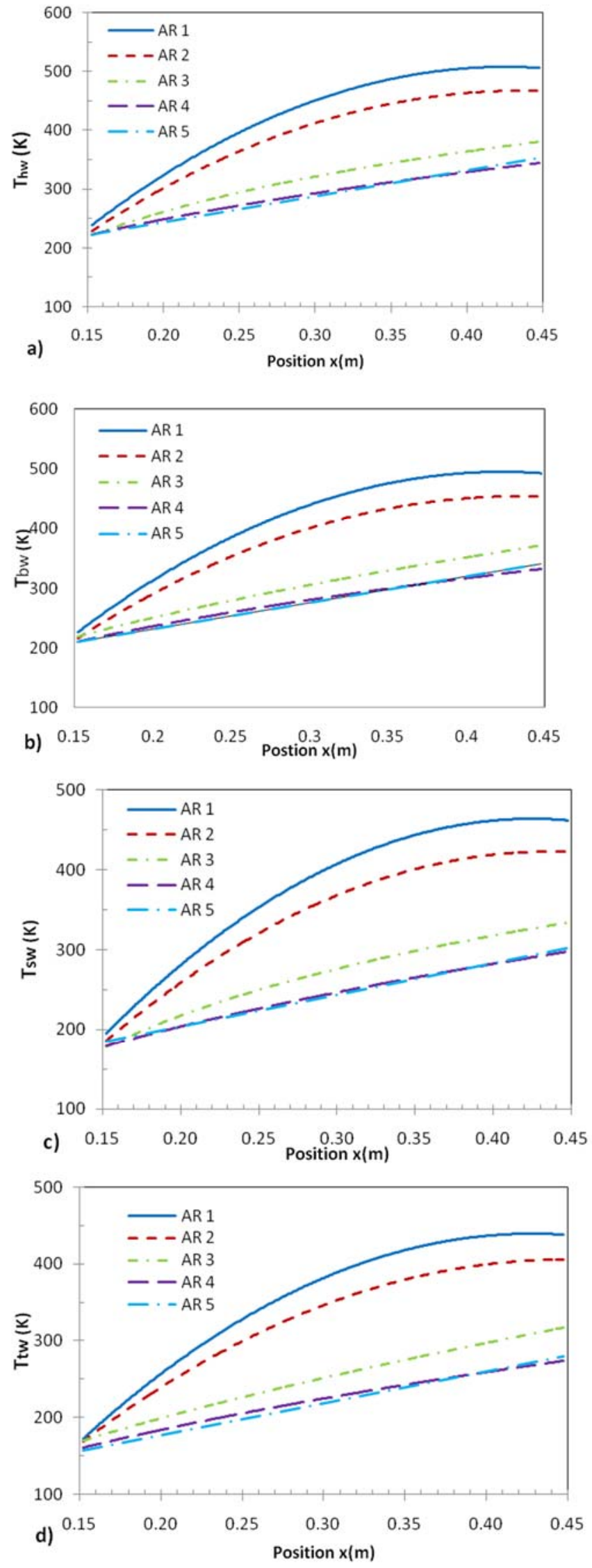

Fig. 13 Variation of average temperatures in the axial direction for different aspect ratios a) heated wall b) bottom wall c) side wall d) top wall

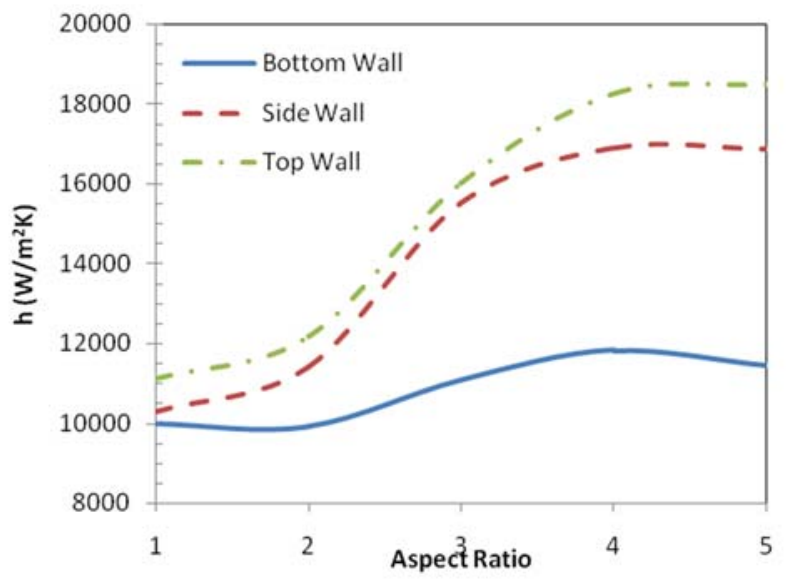

Fig. 14 Variation of wall heat transfer coefficient with aspect ratio.

It is observed that the heat transfer coefficients at all walls increase with aspect ratio. However this increase is marginal when the aspect ratio is increased from 4 and 5 . The heat transfer coefficient along the flow direction for a particular aspect ratio will generally decrease. This reducing trend is caused mainly due to the increase in wall temperature along the flow direction. The rise in wall temperature is faster compared to the rise in bulk fluid temperature. Among the five aspect ratios, the average values of heat transfer coefficients at bottom and side walls are maximum for aspect ratio 4 . The average value of surface heat flux through bottom, side and top walls decrease as the aspect ratio is increased from 1 to 5 and the corresponding reductions are $39 \%, 25 \%$, $32 \%$ respectively. For aspect ratio 1 beyond an axial distance of $0.425 \mathrm{~m}$ a slight increase in heat transfer coefficient is observed for bottom, side and top walls. This may be due to reduction in density of methane which in turn results in increased velocity. A similar trend in heat transfer coefficient is observed for AR 2 at bottom top and side walls. For aspect ratio 4 a slight increase in heat transfer coefficient is observed at the bottom wall. This is mainly due to the improvement in volumetric heat capacity as discussed in the earlier session.

The Nusselt number is defined as

$N u_{b}=\frac{h_{b w} D}{\lambda_{b}}$

The variation of Nusselt number at the bottom surface of the channel in the axial direction is shown in Fig. 16. It is found that for all aspect ratios the Nusselt number decrease in the axial direction up to a distance of about $0.35 \mathrm{~m}$ and then increases. Enhancement in average Nusselt number is observed as the aspect ratio is increased from 1 to 4 . However the Nusselt number decreases marginally when the AR is increased from 4 to 5 , this is mainly due to the reduction in heat transfer coefficient beyond aspect ratio 4 for the bottom wall. From these studies it can be seen that from the heat transfer point of view the optimum value of AR is 4 .

The applicability of the Modified Jackson relation and Bishop Equation Ruan and Meng (2012) were studied for their suitability for supercritical heat transfer of cryogenic methane. The modified Jackson and Hall expression established in Wang et.al. (2010) can be written in the following form

$$
\begin{aligned}
& N u_{b}=0.015 R e_{b}^{0.82} \operatorname{Pr}_{b}^{0.5}\left(\frac{\rho_{w}}{\rho_{b}}\right)^{0.3}\left(\frac{\overline{C_{p}}}{C_{p b}}\right)^{n} \\
& N u_{b}=\frac{h D_{h}}{\lambda_{b}} \\
& \overline{C_{p}}=\left(H i_{w}-H i_{b}\right) /\left(T_{w}-T_{b}\right) \\
& \text { where } \mathrm{n} \text { is defined as } \\
& 0.4 \text { for } \mathrm{T}_{\mathrm{b}}<\mathrm{T}_{\mathrm{w}}<\mathrm{T}_{\mathrm{pc}} \text { Or } 1.2 \mathrm{~T}_{\mathrm{pc}} \leq \mathrm{T}_{\mathrm{b}}<\mathrm{T}_{\mathrm{w}} \\
& 0.4+0.2\left(\frac{T_{w}}{T_{p c}}-1\right) \text { for } \mathrm{T}_{\mathrm{b}} \leq \mathrm{T}_{\mathrm{pc}}<\mathrm{T}_{\mathrm{w}} \\
& 0.4+0.2\left(\frac{T_{w}}{T_{p c}}-1\right)\left[1-5\left(\frac{T_{b}}{T_{p c}}-1\right)\right] \\
& \text { for } \mathrm{T}_{\mathrm{pc}}<\mathrm{T}_{\mathrm{b}} \leq 1.2 \mathrm{~T}_{\mathrm{pc}} \text { and } \mathrm{T}_{\mathrm{b}}<\mathrm{T}_{\mathrm{wb}}
\end{aligned}
$$



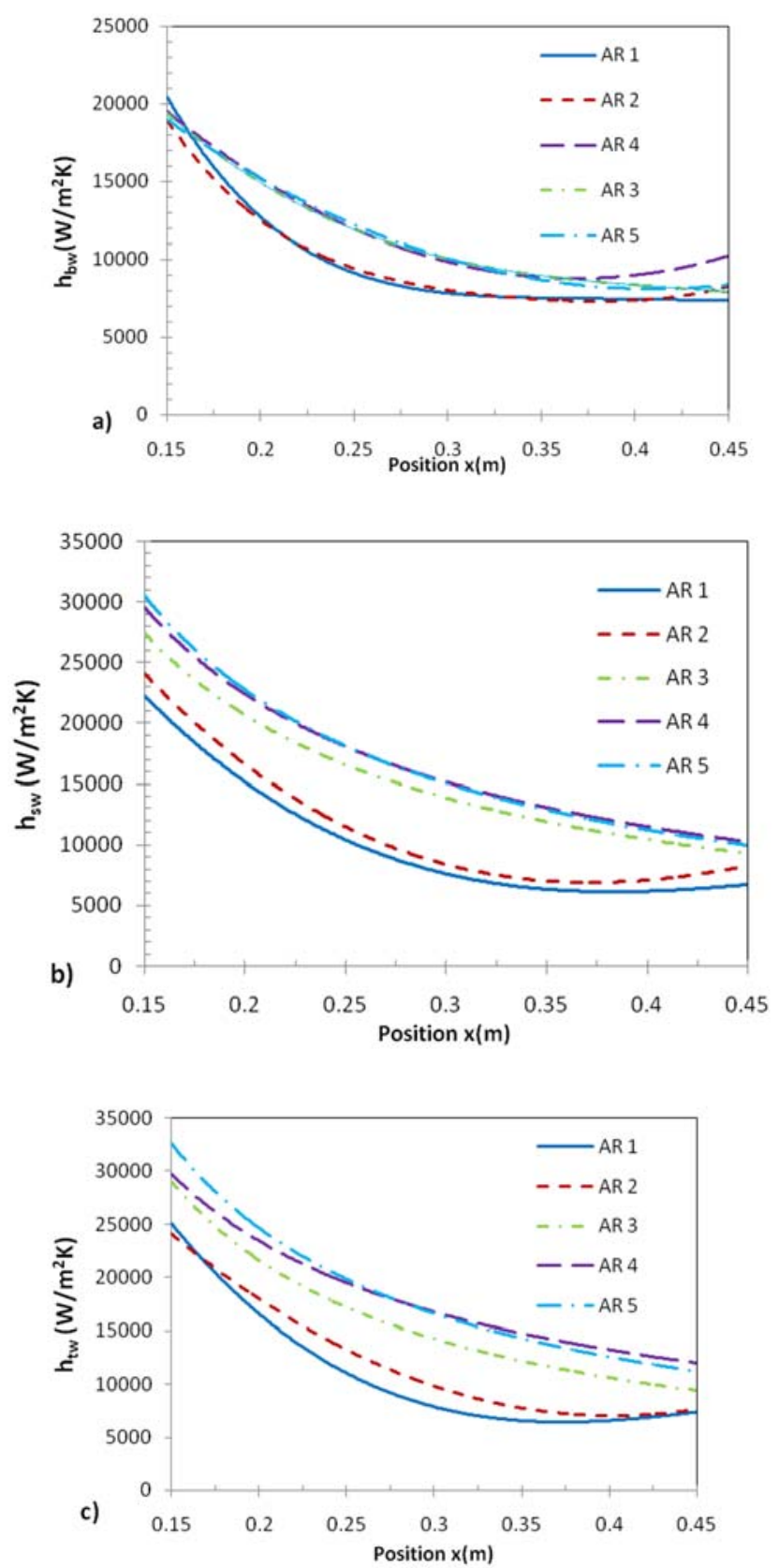

Fig. 15 Variation in heat transfer coefficients in the axial direction for various aspect ratios a) bottom wall b) side wall c) top wall.

\subsection{Variation in Nusselt Number}

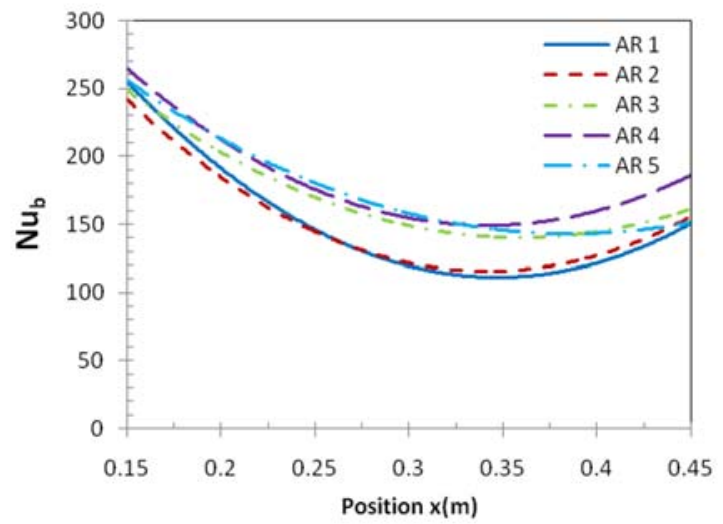

Fig. 16 Variations in Nusselt number with aspect ratios.
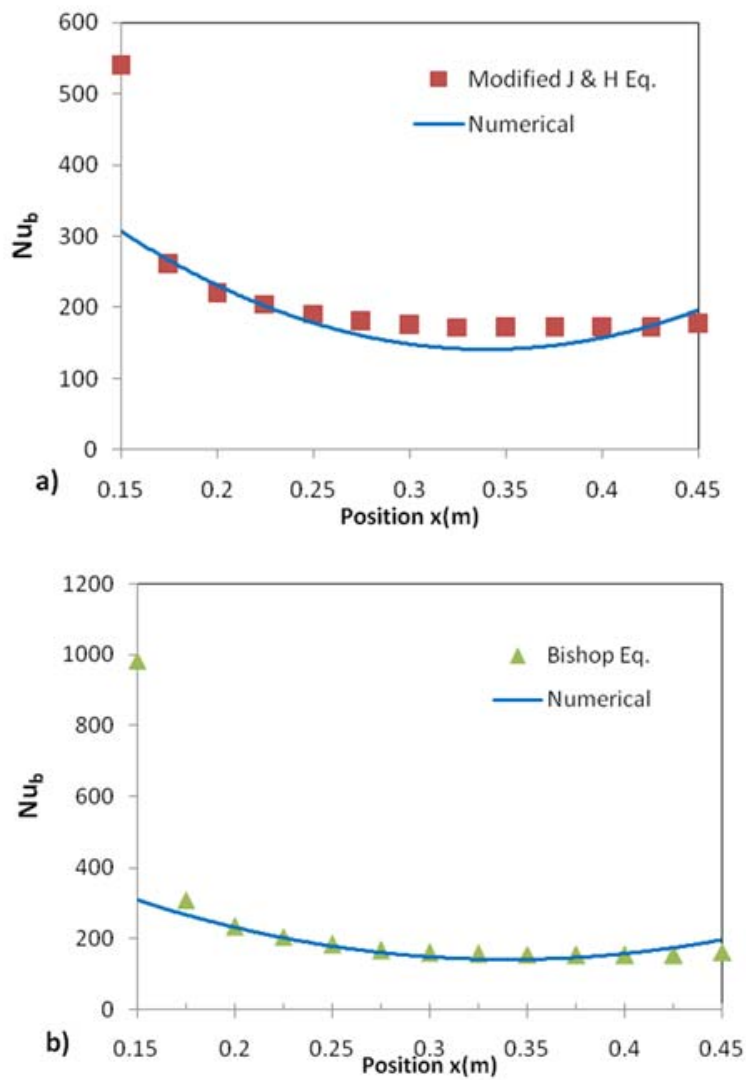

Fig. 17 Variation of Nusselt number in the axial direction a) Modified Jackson and Hall equation, and b) Bishop equation.

The Bishop correlation can be expressed in the following form.

$N u_{b}=0.0069 R e_{b}^{0.9}\left(\overline{\operatorname{Pr}_{b}}\right)^{0.66}\left(\frac{\rho_{w}}{\rho_{b}}\right)^{0.43}\left(1+2.4 \frac{D_{h}}{x}\right)$

$\overline{P r_{b}}=\frac{\mu_{b} \overline{C_{p}}}{k_{b}}=\frac{\operatorname{Pr} \overline{C_{p}}}{C_{p b}}$

The values of Nusselt number obtained for aspect ratio 4 is compared with that obtained from modified Jackson and Hall and Bishop equation and the same is illustrated in Fig. 17.

The results obtained from the present studies is in good agreement with that obtained from empirical correlations except in the thermal entry region. At thermal entry region the wall temperatures are either in the critical region or nearer to it. Due to the sharp property variations in the pseudo critical range both the equations need further refinement to capture the thermal entry effects.

The deviation in the thermal entry region between two set of data is $35 \%$ for Modified Jackson and Hall equation and that for the Bishop equation, it is $-64 \%$. The values of Nusselt number for all other region are in good agreement with the empirical equations and relative error between Modified Jackson and hall and numerical studies is between $20 \%$ to $+5 \%$. The relative error between Bishop equation and numerical results is between $-26 \%$ to $+13 \%$.

\section{CONCLUSIONS}

In this paper, three dimensional turbulent convective heat transfer of cryogenic methane flowing inside the cooling channel of the combustion chamber part of a subscale rocket engine is numerically investigated. Effects of aspect ratio on wall temperature, bulk fluid temperature, heat transfer coefficient and Nusselt number and thermal stratification effects were studied. The present study incorporates accurate evaluation of thermal and transport properties of methane at various temperatures. The variation in properties of wall material with temperature is also taken into account. The numerical results were compared with Modified Jackson 
and Hall and Bishop empirical expressions for their applicability towards supercritical heat transfer at elevated pressure for actual channel orientations. The heat flux distributions through different channel walls were also examined. The following conclusions could be reached.

1. Variation in aspect ratio could produce significant effects on wall temperature, owing to the redistribution of the heat flux.

2. Better heat flux redistribution at higher aspect ratios results in uniform temperature of the coolant at the exit region of the channel

3. The value of optimum aspect ratio is 4 and the average heated wall temperature reduces by $32 \%$ as the aspect ratio increases from 1 to 4 . The reduction in heated wall temperature narrows down from aspect ratio 3 onwards.

4. For $\mathrm{AR}=1,26 \%$ of the heat input is distributed through the bottom wall. As the aspect ratio increases quantity of heat transferred to the fluid through the bottom wall reduces.

5. Average value of heat transfer coefficients at bottom and side walls are maximum at aspect ratio 4.

6. Average value of Nusselt number at the bottom wall increases by $20 \%$, as the aspect ratio is increased from 1 to 4 and beyond aspect ratio 4 a slight decrease in its value is observed.

7. Bishop and Modified Jackson and Hall empirical correlations perform equally well when the wall temperatures are above pseudo critical point where property changes are less.

\section{NOMENCLATURE}

A Channel area, $\mathrm{m}^{2}$

C constants in turbulent model

$\mathrm{C}_{\mathrm{p}} \quad$ constant pressure heat capacity, $\mathrm{J} / \mathrm{kgK}$

D channel hydraulic diameter, $m$

et total internal energy, $\mathrm{J} / \mathrm{kg}$

$\mathrm{G}$ mass flow rate per unit area, $\mathrm{kg} / \mathrm{m}^{2}$

$\mathrm{G}_{\mathrm{k}} \quad$ turbulent generation term

$\mathrm{H} \quad$ channel height, $\mathrm{mm}$

Hi enthalpy, $\mathrm{J} / \mathrm{kg}$

$\mathrm{h}$

$\mathrm{k}$

$\mathrm{Nu}$

$\mathrm{P}$

$\operatorname{Pr}$

Re

$\mathrm{T}$

u

W

$\mathrm{x}$

Greek

Subscripts

b bulk parameter

bw parameters at the bottom wall

eff effective parameters in turbulent flows

hw parameters at the heated wall

pc pseudo critical parameter

sw parameters at the side wall

$\mathrm{t}$ turbulent parameter

tw parameters at the top wall

w wall

\section{REFERENCES}

Carlile, J., and Quentmeyer, R., 1992, “An Experimental Investigation of High Aspect Ratio Cooling Passages," AIAA Paper 92-3154, In $28^{\text {th }}$ AIAA/SAE/ASME/ASEE Joint Propulsion Conference and Exhibit.

Ely, J. F., and Hanley, H. J. M., 1981, "Prediction of Transport Properties. 1. Viscosity of Fluids and Mixtures," Industrial and Engineering Chemistry Fundamentals, 20(4), 323-332 http://dx.doi.org/10.1021/i100004a004

Ely, J. F., and Hanley, H. J. M., 1983 "Prediction of Transport Properties. 2. Thermal Conductivity of Pure Fluids and Mixtures," Industrial and Engineering Chemistry Fundamentals, 2(1), 90-97. http://dx.doi.org/10.1021/i100009a016

Hua, Y. X., Wang, Y. Z., and Meng, H., 2010, “A Numerical Study of Supercritical Forced Convective Heat Transfer of $n$-Heptane inside a Horizontal Miniature Tube," The Journal of Supercritical Fluids, 52(1), 36-46.

Hongfang Gu, Hongzhi Li, Haijun Wang, Yushan Luo, 2013, "Experimental Investigation on Convective Heat Transfer from a Horizontal Miniature Tube to Methane Supercritical Pressures," Applied Thermal Engineering, 58, 490-498. http://doi.org/10.1016/i.applthermaleng.2013.04.049

He, S., Jiang, P. X., and Xu, Y. J., Shi, R.-F., Kim, W. S., and Jackson, J. D., 2005, "A Computational Study of Convection Heat Transfer to $\mathrm{CO} 2$ at Supercritical Pressures in a Vertical Mini Tube," International Journal of Thermal Sciences, 44(6) 521-530.

http://dx.doi.org/10.1016/j.ijthermalsci.2004.11.003

Jose Prakash, M. et al., 2012, "Numerical Studies on Combustion in a Film Cooled Semi-Cryogeinic Rocket Thrust Chamber," AIAA Paper 2012- 4167, , In 48 ${ }^{\text {th }}$ AIAA/SAE/ASME/ASEE Joint Propulsion Conference and Exhibit.

Jiang, P.X., Xu, Y.J., Lv, J., Shi, R.F., He, S., and Jaclson, J.D., 2004, "Experimental Investigation of Convection Heat Transfer of $\mathrm{CO} 2$ at Supercritical Pressures in Vertical mini tubes and in Porous media," Appl. Thermal Engineering, 24, 1255-1270.

http://doi.org/10.1016/j.applthermaleng.2003.12.024

Koshizuka, S., Takano, N., and Oka Y., 1995, "Numerical Analysis of Deterioration Phenomena in Heat Transfer to Supercritical Water," International Journal of Heat and Mass Transfer, 38(3), 3077-3084. http://dx.doi.org/10.1016/0017-9310(95)00008-W

Lee, S. H., and John, R. Howell, 1996, "Laminar Forced Convection at Zero Gravity to Water near the Critical Region," Journal of Thermophysics and Heat Transfer, 10(3), 504-510. http://dx.doi.org/10.2514/3.817

Liao, S. M., and Zhao, T. S., 2002, “An Experimental Investigation of Convection Heat Transfer to Supercritical Carbon Dioxide in Miniature Tubes," International Journal of Heat and Mass Transfer, 45(2), 50255034.

http://doi.org/10.1016/S0017-9310(02)00206-5

Pizzarelli, M., Nasuti, F., and M. Onofri, M., 2007, "A Simplified Model for the Analysis of Thermal Stratification in Cooling Channels," Session 5.02, In 2nd European Conference for Aerospace Sciences.

Pizzarelli, M., Nasuti, F., and Onofri, M., 2008, "Flow Analysis of Transcritical Methane in Rectangular Cooling Channels," AIAA Paper 2008-4556.

Pizzarelli, M., Nasuti, F., and M. Onofri, M., 2009, "Investigation of Transcritical Methane Flow and Heat Transfer in Curved Cooling Channels," AIAA Paper 2019-5304, In 45 Joint Propulsion Conference and Exhibit. 
Pizzarelli, M., Urbano, A., Nasuti, F., and M. Onofri, M., 2009, "CFD Analysis of Heat Transfer to Transcritical Fluids in Liquid Rocket Engines," ESA SP-659, In $6^{\text {th }}$ European Symposium on Aerotheromodynamics for Space Vehicles.

Pizzarelli, M., Urbano, A., and Nasuti, F., 2010, "Numerical Analysis of Deterioration in Heat Transfer to Near-Critical Rocket Propellants," Numerical Heat Transfer, Part A: Applications: An International Journal of Computation and Methodology, 57(5), 297-314. http://dx.doi.org/10.1080/10407780903583016

Pizzarelli, M., Betti, B., and Nasuti, F., 2011, "Coupled analysis of hotgas and Coolant flows in LOX/methane Thrust chambers," In $4^{\text {th }}$ European Conference for Aerospace Sciences.

Pizzarelli, M., Nasuti, F., and M. Onofri, M., 2012, "CFD Analysis of Transcritical Methane in Rocket Engine Colling Channels," Journal of Supercritical Fluids, 62, 79-87.

http://doi.org/10.1016/j.supflu.2011.10.014

Pizzarelli, M., Nasuti, F., Onofri, M., Roncioni, P., Votta, R., Battista F. , 2013, "Supercritical Methane Heat Transfer Modeling in Rocket Engine Cooling Channels," AIAA Paper 2013-3995, In $49^{\text {th }}$ AIAA/SAE/ASME/ASEE Joint Propulsion Conference.

Pizzarelli, M., Nasuti, F., and Onofri, M., 2013 "Trade-off Analysis of High-Aspect-Ratio-Cooling-Channels for Rocket Engines," International Journal of Heat and Fluid flow, 44, 458-467. https://doi.org/10.1016/j.ijheatfluidflow.2013.08.003

Pizzarelli, M., Nasuti, F., and Onofri, M., 2014, "Effect of Cooling Channel Aspect Ratio on Rocket Thermal Behavior," Journal of Thermophysics and Heat Transfer, 28(3), 410-416. http://dx.doi.org/10.2514/1.T4299

Pizzarelli, M., Nasuti, F., Onofri, M., Roncioni, P., Votta, R., Battista F., 2015, "Heat Transfer Modeling for Supercritical Methane flowing in Rocket Engine Cooling Channels," Applied Thermal Engineering, 75, 600-607.

https://doi.org/10.1016/j.applthermaleng.2014.10.008

Pizzarelli, M., 2016, "A CFD Derived Correlation for Methane heat Transfer deterioration," Numerical Heat Transfer, Part A: Applications, 69(3), 242-264.

https://doi.org/10.1080/10407782.2015.1080575

Ruan B., Meng H., 2012, "Supercritical Heat Transfer of CryogenicPropellant Methane in Rectangular Engine Cooling Channels," Journal of Thermophysics and Heat Transfer, 26(2), 313-321.

https://doi.org/10.2514/1.T3670

Votta, R., Battista, F., Salvatore, V., Pizzarelli, M., Lecceseb, G., Nasuti, F., and, Meyerc, S., 2016, "Experimental Investigation of Transcritical Methane flow in Rocket Engine Cooling Channel," Applied Thermal Engineering, 1-22.

http://dx.doi.org/10.1016/j.applthermaleng.2015.12.019

Simon, N. J., Drexler, E. S., Reed, R. P., 1992, "Properties of Copper Alloys at Cryogenic Temperatures," NIST Monograph 177.
Trejo, A., Gracia, C., Galvan, M., and Choudhuri, A., Melcher, J., Bruggemann, J. 2013, “An Experimental Investigation on the Steady State Heat Transfer Characteristics of Liquid Methane," AIAA Paper 2013-4145, In 49 th $^{\text {AIAA/SAE/ASME/ASEE Joint Propulsion }}$ Conference.

Trejo, A., Garcia, C., Galvin, M., Choudhuri, A., 2014 "Experimental I nvestigation of Liquid Methane Convection and Boiling in Rocket Engine Cooling Channels," AIAA paper 2014-4007, In 50 th AIAA/SAE/ASME/ASEE Joint Propulsion Conference.

Urbano, A., Pizzarelli, M., and Nasuti, F., 2009, "Numerical Analysis of Transcritical Fluids Heating in Liquid Rocket Engine Cooling Channels," The Journal of Aerospace Science Technology Systems, $\mathbf{8 8}$ (1/2), 20-30.

Urbano, A., and Nasuti, F., 2012, "Parametric Analysis of Heat Transfer to Supercritical-Pressure Methane," Journal of Thermophysics and Heat Transfer, 26(3), 450-463.

https://doi.org/10.2514/1.T3840

Urbano, A., and Nasuti, F., "Conditions for the occurrence of Heat transfer Deterioration in Light Hydrocarbon Flows," 2013, International Journal of Heat and Mass Transfer, 65, 599-609. https://doi.org/10.1016/j.ijheatmasstransfer.2013.06.038

Woschnak, A., Suslovy, D., and Oschwald, M., 2003, "Experimental And Numerical Investigations of Thermal Stratification Effects," AIAA Paper 2003-4615, In 39 ${ }^{\text {th }}$ AIAA/SAE/ASME/ASEE Joint Propulsion Conference and Exhibit.

Wang, Y. Z., Hua, Y. X., and Meng, H., 2010, "Numerical Study of Supercritical Turbulent Convective Heat Transfer of Cryogenic Propellant Methane," Journal of Thermophysics and Heat Transfer, 24(3), 490-500.

https://doi.org/10.2514/1.46769

Wang L., Chen Z and Meng H., 2013, "Numerical Study of Conjugate Heat Transfer of Cryogenic Methane in Rectangular Engine Cooling Channels at Supercritical Pressures," Applied Thermal Engineering, 54, 237-246.

https://doi.org/10.1016/j.applthermaleng.2013.02.007

Yamagata et al., 1972, "Forced Convective Heat Transfer to Supercritical Water Flowing in Tubes," International Journal of Heat and Mass Transfer, 15, 2575-2593. https://doi.org/10.1016/0017-9310(72)90148-2

Younglove, B. A., and Ely, J. F., 1987, "Thermophysical Properties of Fluids II. Methane, Ethane, Propane, Isobutane, and Normal Butane," Journal of Physical and Chemical Reference Data, 16(4) 577-796. https://doi.org/10.1063/1.555785

“Ansys Fluent 14.5 User's Guide”, Ansys, Inc., Canonsburg USA, 2012.

“Ansys Meshing 14.5 User's Guide”, Ansys, Inc., Canonsburg USA, 2012.

NIST Standard Reference Data base Number 69. 